\title{
On Cultivating College Students' Humanistic Qualities in Western Fine Arts Appreciation Course
}

\author{
Rong Zhuang \\ School of Art, Jiangsu University \\ 301 Xuefu Road, Zhenjiang 121013, China \\ Tel: 86-511-8879-1205Ｅ-mail: jsdxzjf@163.com
}

\begin{abstract}
In recent years, western pragmatism has been prevalent on the campuses of Chinese universities. Its direct result is the emergence of such a trend in fine arts teaching which attaches high importance to the pragmatic side of the art learning and disregards fostering the humanistic qualities of the students. One of the most serious phenomena of this trend is that cultivating college students' humanistic qualities has been duly neglected. This paper attempts to discuss the possible causes of this phenomenon from both subjective and objective perspectives, illustrating the great importance of western fine arts appreciation course on cultivating students'character. It attempts to unite cultivating college students' humanistic qualities and art education together theoretically and practically in order to change the present situation of art teaching, some solutions and suggestions concerning course arrangement and teaching are also offered.
\end{abstract}

Keywords: Fine arts teaching, College students, Cultivating, Humanistic qualities

\section{Introduction}

Modern China after opening-up policy has become famous for its emphasis on education. Its enthusiastic embrace of a strong educational system made it possible for the country to rise from the ashes of the Cultural Revolution and during the ensuing 30 years rebuild itself as one of the world's top economic powers, with affluence and freedom firmly in its grasp. China has recently been the focus of a great deal of international attention, not only from those concerned with politics and economics, but also from people interested in the field of education. One source of such attention is the western thought, who through the force of the industrial revolution became a great economic power, but now suffer from what is often referred to as "western pragmatism" and are earnestly trying to pull themselves out of this quagmire. In debates about educational reform, China is often cited as a good example; it is an economic success, and the foundation of that success is thought to be its superior system of education. In comparative studies of science and math proficiency in different countries, China is always in the top ranks. The high proficiency levels of Chinese students are seen as signs of an efficient education system. This is not only something to be happy about, but also something that those born in China can be proud of.

All the same, we find the recent tendency to forget the spiritual side of life and make light of morality truly lamentable. Especially in recent years, western pragmatism has been prevalent on the campuses of Chinese universities. Its direct result is the emergence of such a trend in fine arts teaching which attaches high importance to the pragmatic side of the art learning and disregards fostering the humanistic qualities of the students. One of the most serious phenomena of this trend is that cultivating college students' humanistic qualities has been duly neglected.

\section{The importance of cultivating college students' humanistic qualities}

To counter the above phenomenon, we would like to take a look at the present state of education in China and, think about what kind of education we need for the future.Western fine arts appreciation course, a branch of art education curriculum, has existed for a long time. In traditional class, art education is to appreciate art such as painting, singing, dancing. In such a class, students are taught to knowledge of art, skills and technical ability. Art, as an accomplishment of human being's cognition, is treated as an entity and enclosed in a small area, ignoring people's attitude, feelings, experience. The outcome of such a teaching method is as the follows: most college students believe that the only task of an artist is to create beautiful things like paintings, sculptures, and so on without paying attention to the feeling and spirits of most common people.

New curriculum reforms are now being carried out in many universities, aiming at changing the knowledge-orientation of curriculum, emphasizing the shape-up of students' active attitude of studying, turning the course of acquisition of basic knowledge and skills to the course of configuration of right value outlook, cultivating students' abilities of analyzing and solving problems and abilities of interaction and cooperating, encouraging students to feel and appreciate the beauty of life ,nature, and science. The notion of education is changed, learning and teaching styles should be changed accordingly. 
In fact, beauty universally exists around the world where human beings acknowledge. Everyone tastes the world by his own way. Appreciation is internal spiritual demand of people and it connects not only with one's moral standards of behaviors, world outlook, life attitude, but also with one's state of mind. So appreciation of beauty is an individual's spiritual activity. It is affected by one's experience and cognitive competence. For instance, people have different opinions on paintings of modernism. Some people may not stand it, while some may love it to their death. Everyone appreciates the beauty of a painting by his own way and makes his own judgment. The judgment generates and becomes his experience. The experience will affect his later appreciation of beauty. When he accumulates the experience to a certain amount, his concept of appreciation of beauty comes into being. Configuration of the concept heralds of configuration of his deep psychological structure, that is, his moral standards of behavior and world outlook. This deep psychological structure is stable than before, but is relative and can be changed. Therefore appreciation of beauty is human beings' spiritual activity. It is arbitrary and connects with the formation of one's world outlook. Vise versa. If measures are taken to influence college students' appreciation, their deep psychological structure will come into being. Moreover, it will be good for the moulding of their good characters. In terms of aesthetic education, appreciation of beauty is a way by which college students' humane qualities can be strengthened, their discerning power can be promoted and their potential intelligence can be stimulated.

The tasks of art education are to develop students' sense of appreciation of beauty and ability and train their creativity. The essence of appreciation of beauty is to continually transcend the limits of the selves. Its aim is to shock students' mind, soul as well as characters, accelerates the growth of students' spiritual life. It enlarges connotation and denotation of art education and deepens human being's cognition of appreciation of beauty. The activities of appreciation of art provide entrance for the inspiration and expressions of lives.

As mentioned above, Western fine arts appreciation course is a kind of education of feelings which focus on tasting and puts emphasis on perceptual education. Appreciation is a special active value-orientation activity of human being's. The standards of value of art education firstly must be beauty as well as truth and virtue. The more one has improved his humanistic quality, the better he could appreciate fine arts, especially Western fine arts, for arts are humanistic products.

\section{Approaches to cultivating college students' humanistic qualities}

Western fine arts appreciation course is a union of art teaching and humanistic education, feelings and tasting is one of its properties. It aims at shaping up students' good characters, life attitude, and perfect personalities. Teaching of appreciation of beauty is a sophisticated cognition styles. It is different from rational cognition and logical reason. So feelings and tasting are treated as a principle. There are many essential methods for improving students' humanistic quality, among them are following ones.

\subsection{Using various and interesting activities}

It is effective and functional to apply various and interesting activities with moderate challenge to attract students to arouse their curiosity in art appreciation. If the students can realize that art appreciation can be interesting and fun with their involvement in the process, they will be willing to participate in Western fine arts appreciation course. Numerous solo and group exhibitions in different cities are welcome to college students.

Exhibitions are a rich source of new ideas and applications and, as such, play an important role in strategic planning and business generation. Exhibitions are a focal point for industry, attracting a broad cross-section of representatives, from buyers and sellers, to trade associations and the media. A full program of associated activities provides a wealth of additional networking opportunities from seminars and social events, to competitions and award ceremonies. As paintings depict landscapes and folk activities of different countries and regions, the painters' unique individual styles is reflected in their strokes, colors and lights. Exhibitions allow students to put their book knowledge comprehensively to the practice easily by examining the art products for themselves, and comparing and contrasting different creators' performance, Exhibitions are a recognized launch pad for new products, and an extremely time-efficient way to keep the students to date with the latest innovations. Well-chosen exhibitions are valuable activities as they give students a chance to improve their humanistic spirits and at the same time allow students to practice their art appreciation skills. Teachers can compile a wide range of various and interesting activities in a concentrated period of time to encourage students to involve as much of the time and effort as possible so as to employ meaningful and useful appreciation skill and improve college students' humanistic qualities.

\subsection{Involving new and effective techniques}

As some techniques have been employed in teaching, there are more choices and more methods for teachers to stimulate students' intrinsic motivation, among them is computer assisted teaching, that is, with the help of multimedia, Internet and educational software, to stimulate college students' humanistic qualities. These methods are innovative, interesting, practical and effective with colorful pictures, vivid voices, plentiful information and effective interaction that arouse students' curiosity and interest in art appreciation and promote their intrinsic motivation. With intrinsic motivation, many students can start self-study in schools or at homes to effectively improve their humanistic qualities. 
Computer assisted teaching offers multi-media enhanced state of the art teaching and learning materials, individualized programmed instruction that guarantees college students' success in mastering knowledge. Internet provides an enriched worldwide learning environment with access to worldwide knowledge webs to extend and enrich students' learning experience. The focus is the learner, rather than the teacher and on students' mastery of material through interactive teaching and learning. Computer assisted teaching increases students' computer skills necessary for success in the workforce. Core skills for today's workplace include the challenges of creatively using the "information highway" to critically analyze information, solve problems and communicate with others.

\subsection{Creating a relaxed and positive learning climate}

Climate is important because it creates an environment that encourages both achievement and motivation (Raviv, Ravivi, \& Reisel, 1990, p457). From the view

of Maslow's hierarchy theory, motivation and need are of great importance in learning, a relaxed and positive learning climate should be providing for college students' art appreciation course. In a friendly atmosphere, students can feel secure and their sense of understanding and learning motivation can be promoted.

Teachers should allow students to discuss broadly without the fear of expressing their own thoughts different from others besides every lecture. When students make some mistakes, teachers should describe them with warm comments, with more smiles and encourages, teachers can have more interactions and stand closer to students. And when students are dealing with the tasks, teachers should prepare to give supportive aids at any moment.

\subsection{Cultivating college students' five virtures of afftection, justice, courtesy, wisdom and sincerity}

To transform our current education system, with its overemphasis on intellectual training, into one that produces persons who live up to the ideal of what man should be, we would like to propose the following educational goals centered on the five Confucian virtues of affection, justice, courtesy, wisdom and sincerity. Affection means helping each other and nurturing a compassionate heart; Justice means not behaving unfairly and doing what you feel is right; Courtesy means using honorific language to your superiors and nurturing personal humility; Wisdom means acquiring correct knowledge about a variety of things and nurturing sound judgment ; Sincerity means never deceiving and dealing with others with sincerity.

To make sure that these five universal virtues are acquired, college students need to be taught in a gradual manner and in a variety of situations. Moreover, at home, school, and in society, students should be taught that they should become adults who are useful to others and to society, and they should be encouraged to actually try to act that way in all three areas. If teachers can do this, we believe they can create a more humane society.

It must be re-emphasized in conclusion that the issue of humanistic quality cultivating is far from simple, and there are no simple solutions to the questions of how to improve college students' humanistic spirits. The aim of Western art appreciation lies not in the mastery of strategies but in heightening students' humanistic awareness, in enhancing the ability to self-monitor and self-regulate in the learning process as well as humanistic quality improvement.

\section{Conclusion}

It is quite clear that humanistic quality enhancement is very important to both the teachers of art in college and their students. As teachers of art, we should flexibly carry out different teaching approaches to improve the quality of 45-minute class, and take an active part in art teaching innovation so that college students should be aware of the importance of cultivating their humanistic ability in their daily studies.

Western fine arts appreciation course aims at shaping up students' good characters, life attitude, and perfect personalities. It is a sophisticated cognition styles which is different from rational cognition and logical reason.

Generally speaking, teaching aims, teaching contents, teaching organization and method as well as textbooks, should be in pursuit of humanistic quality enhancement. Students are edified by the materials and enlightened their intelligence. They are attracted by the approach of beauty and stimulated the desire of seeking knowledge.

In conclusion, like building a house, cultivating college students' humanistic qualities takes some time, just as the saying goes, Rome was not built in a day. With the help of the teachers, as long as students command a good knowledge of the world, the humanistic spirits of students is surely to be greatly improved.

\section{References}

Bandura. (1977). A. Self-efficacy: Toward a Unifying Theory of Behavioral Change. Psychological Review, (84): 191-215.

Mertens, D. M. (1998). Research Methods in Education and Psychology: Integrating Diversity with Qualitative and Quantitative Approaches. Thousand oaks, London: Sage Publications.

Zimmerman,B. J. (2000). Self-efficacy: An Essential Motive to Learn.Contemporary Education Psychology, (25): 
82-91.

Wenxue Zhou. (2007). 16, 02. Research on humanistic quality education for postgraduate students in science \& engineering universities. Journal of Inner Mongolia Polytechnic University (Social Science Edition).

Wenning Zhou. (2006). volum 16, 14. Talking about the Higher Education and Talents Cultivation under the New Situation. Sci-Tech Information Development \& Economy. 